\title{
Magnesium augments immunosuppressive effects of a corticosteroid in obese mice with airway inflammation
}

\author{
Jundong Moon, ${ }^{1}$ Eun-Sang Cho, ${ }^{2}$ Mee-Young Lee, ${ }^{3}$ Hwa-Young Son, ${ }^{4}$ Kyoungyoul Lee ${ }^{1}$
}

\begin{abstract}
Background: Magnesium deficiency common in obesity is known to promote chronic low-grade inflammation and aggravate asthma symptoms; however, the effects of magnesium supplementation in obese asthmatic patients have not been investigated.
\end{abstract}

Objective: To examine the effects of magnesium co-administration with dexamethasone on airway inflammation in obese mice.

Methods: Female C57BL/6 mice were fed a high-fat diet, sensitized with ovalbumin (OVA) to induce allergic reactions, challenged with aerosolized OVA, and administered dexamethasone $(3 \mathrm{mg} / \mathrm{kg})$ with or without magnesium. Bronchial inflammation was analyzed based on the presence of inflammatory cells and cytokines in bronchoalveolar lavage fluid, total and OVA-specific IgE in serum, goblet cells ratios, bronchial wall thickness, and expression of $a$-smooth muscle actin.

Results: In obese mice, co-administration of magnesium and dexamethasone decreased IL-13 in bronchoalveolar lavage fluid and total and OVA-specific IgE in serum, and reduced $\alpha$-smooth muscle actin-positive areas in the bronchi compared with mice treated with dexamethasone alone. However, no differences were observed in dexamethasone-treated normal-weight mice depending on magnesium supplementation.

Conclusion: These results suggest that magnesium increases immunosuppressive effects of dexamethasone in airway inflammation aggravated by obesity, suggesting that magnesium supplementation may have a potential in alleviating asthma symptoms in obese patients with reduced responses to corticosteroids.

Key words: magnesium deficiency, ovalbumin, asthma, obesity, chronic low-grade inflammation

\footnotetext{
From:

${ }^{1}$ Department of Emergency Medical Service College of Health \& Nursing, Kongju National University, Chungnam, Republic of Korea

${ }^{2}$ Chemicals Toxicity Research Bureau, Occupational Safety and Health Research Institute, Korea Occupational Safety and Health Agency, Daejeon, Republic of Korea

K-herb Research Center, Korea Institute of Oriental Medicine, Daejeon, Republic of Korea

${ }^{4}$ Department of Veterinary Pathology, College of Veterinary Medicine, Chungnam National University, Daejeon, Republic of Korea
}

Corresponding author:

Jundong Moon

Department of Emergency Medical Service College of Health \& Nursing, Kongju National University, 56 GonjuDaehak-ro, Gongju,

Chungnam 314-701, Republic of Korea

E-mail: jdm02@kongju.ac.kr

\section{Introduction}

The incidence of obesity and asthma continues to rise worldwide and many epidemiological studies revealed positive correlation between excessive weight and asthma. ${ }^{1}$ It was found that the risk for newly diagnosed asthma in obese individuals within one year is 1.51 times higher than that in people with normal weight and increases proportionally with the body mass index. ${ }^{2}$ Obesity has been recognized as a global epidemic with a steadily increasing rate, and obesity-associated asthma has emerged as a major public health problem. Thus, a study conducted in North America found that approximately $75 \%$ of patients who visited the emergency room with acute asthma exacerbation are overweight or obese. ${ }^{3}$ Obese patients with severe asthma show blunted responses to steroids and $\beta$-agonists, ${ }^{4}$ and, thus, do not get sufficient relief during acute asthma attack, indicating that new treatment approaches are urgently needed. Several hypotheses have been proposed 
regarding the association between obesity and asthma, including genetic predisposition and changes in lung mechanics such as reduction of lung compliance, expiratory reserve, and functional residual capacity caused by increased thoracic mass. ${ }^{1,2}$ It has also been suggested that chronic low-grade inflammation induced by adipokines, which are cytokines secreted by adipose tissue, contributes to the severity of asthma-related inflammation, ultimately promoting airway hyper-responsiveness. ${ }^{5}$

Obesity is also a major risk factor for metabolic syndrome, and it has been suggested that obesity-associated deficiency of magnesium $(\mathrm{Mg})$, one of the most important microelements with a role in the immune system, can potentially contribute to the underlying pathological mechanisms. ${ }^{5,6} \mathrm{Mg}$, which causes bronchial smooth muscle relaxation and acts as a weak bronchodilator, is used as an adjunct therapy for asthma treatment and, according to a Cochrane review of randomized clinical trials, can improve lung function in adult patients admitted to the emergency department with exacerbated asthma unresponsive to first-line therapies such as oxygen supplementation, $\beta$-agonists, and corticosteroids. ${ }^{7}$ Several reports suggest that the beneficial effect of $\mathrm{Mg}$ in asthmatic patients is underlain by the attenuation of excessive immune reactivity. ${ }^{89}$ However, most studies on the activity of $\mathrm{Mg}$ in asthma are clinical trials focused on physiological parameters such as respiratory rate, oxygen saturation, and forced expiratory volume 1 (FEV1), and health care quality indicators such as admission and discharge rates, whereas few studies addressed the effects of $\mathrm{Mg}$ on immune responses in asthma associated with obesity. ${ }^{7}$ As $\mathrm{Mg}$ deficiency is common for obese individuals, it may aggravate airway inflammation and compromise asthma treatment, suggesting that $\mathrm{Mg}$ supplementation may improve the effect of anti-inflammatory drugs such as corticosteroids in obese asthmatic patients.

Therefore, in this study, we aimed to examine the effects of $\mathrm{Mg}$ co-administration with corticosteroids on immune response of obese and normal-weight mice after induction of bronchial inflammation.

\section{Materials and Methods \\ Animals and experimental protocol}

Specific pathogen-free female C57BL/6 mice (7-week-old; mean weight, $16.74 \pm 0.26 \mathrm{~g}$ [control: $16.72 \pm 0.2 \mathrm{~g}$; obese: $16.76 \pm 0.39 \mathrm{~g}]$ ) were purchased from Orient Bio (Kyung-gi, Korea) and allowed to acclimatize in our animal facility under standard laboratory conditions for three days prior to experiments. Then, animals were randomly divided into normal diet group and high-fat diet group, which were provided either standard chow or high-fat (60\% kcal) chow (D12492 Research Diet, New Brunswick, USA), respectively, and water ad libitum for 87 days.

To establish an allergic bronchial asthma model, OVA sensitization and airway challenge were performed as described previously. ${ }^{10}$ Mice were sensitized by intraperitoneal (i.p.) injection of $20 \mu \mathrm{g}$ ovalbumin (OVA, grade III; Sigma-Aldrich, St. Louis, MO, USA) and $2 \mathrm{mg}$ aluminum hydroxide in 200 $\mu \mathrm{L}$ PBS ( $\mathrm{pH} 7.4$ ) on days 120 and 127; PBS injection was used as negative control. After the initial sensitization, mice were exposed to $1 \%$ OVA solution (w/v in PBS) for $20 \mathrm{~min}$ using an ultrasonic nebulizer (NE-U12; Omron Corp., Tokyo, Japan), treated with dexamethasone (Dex; $3 \mathrm{mg} / \mathrm{kg}$ orally) alone or with $\mathrm{MgSO}_{4}(\mathrm{Mg} ; 100$ or $200 \mathrm{mg} / \mathrm{kg}$ i.p.) on days 134,135 , and 136, and sacrificed on day 138. Overall, 10 treatment groups (5 groups per diet, $\mathrm{n}=6$ mice per group) were analyzed. The normal control $(\mathrm{C})$ and obese $(\mathrm{O})$ groups were respectively designated as: $\mathrm{CP}$ and $\mathrm{OP}$, PBS-treated; $\mathrm{CO}$ and OO, OVA-treated; COD and OOD, OVA + Dex; CODM and OODM, OVA + Dex + Mg (100 mg/kg); CODM2 and OODM2, OVA + Dex + double Mg (200 mg/kg), as shown in Table 1.

The study protocol was approved by the Institutional Animal Care and Use Committee (IACUC) at Chungnam National University, and all procedures and methods were conducted in compliance with the regulations stipulated by the IACUC, the NIH Guidelines for the Care and Use of Laboratory Animals, and the National Animal Welfare Law of Korea.

Table 1. Experimental group distribution according to sensitization and treatment

\begin{tabular}{|c|c|c|c|}
\hline & Allergen & Treatment & Group symbol \\
\hline \multirow[t]{5}{*}{ Control mice (normal diet) } & PBS & None & CP \\
\hline & OVA & None & $\mathrm{CO}$ \\
\hline & OVA & Dex & COD \\
\hline & OVA & $\mathrm{Dex}+\mathrm{MgSO}_{4}(100 \mathrm{mg} / \mathrm{kg})$ & CODM \\
\hline & OVA & $\mathrm{Dex}+\mathrm{MgSO}_{4}(200 \mathrm{mg} / \mathrm{kg})$ & CODM2 \\
\hline \multirow[t]{5}{*}{ Obese mice (high-fat diet) } & PBS & None & OP \\
\hline & OVA & None & $\mathrm{OO}$ \\
\hline & OVA & Dex & OOD \\
\hline & OVA & $\mathrm{Dex}+\mathrm{MgSO}_{4}(100 \mathrm{mg} / \mathrm{kg})$ & OODM \\
\hline & OVA & $\mathrm{Dex}+\mathrm{MgSO}_{4}(200 \mathrm{mg} / \mathrm{kg})$ & OODM2 \\
\hline
\end{tabular}

OVA, ovalbumin; Dex, dexamethasone (3 mg/kg). 


\section{Inflammatory cell counts in bronchoalveolar lavage fluid $(B A L F)$}

Mice were sacrificed with an overdose $(50 \mathrm{mg} / \mathrm{kg})$ of pentobarbital and blood was collected from the caudal vena cava. After tracheotomy, BALF was collected by instillation of 0.5 $\mathrm{mL}$ PBS three times through the tracheal cannula, centrifuged at 3,000 $\mathrm{rpm}$ for $10 \mathrm{~min}$, and the supernatant was stored at $-70^{\circ} \mathrm{C}$ until analysis. The total number of inflammatory cells was assessed by counting live and dead cells in a hemocytometer after trypan blue staining. Cell pellets were suspended in $0.5 \mathrm{~mL}$ PBS, and $100 \mu \mathrm{L}$ of each solution was spread onto a slide using a cytospin machine (Hanil Science Industrial, Seoul, Korea), dried, fixed, and stained with Diff-Quik Staining reagent (Merck, Darmstadt, Germany) according to the manufacturer's instructions.

\section{Evaluation of total and OVA-specific IgE levels and cytokines}

Enzyme-linked immunosorbent assay (ELISA) kits were used to measure IL-4, IL-6, and IL-13 (Aviva Systems Biology, San Diego, CA, USA), serum leptin (Merck Millipore, Burlington, MA, USA), and total and OVA-specific IgE (Bethyl Laboratory, Montgomery, TX, USA) according to the manufacturers' instructions.

\section{Histopathology analysis on lung tissue}

After BALF was obtained, lung tissues were fixed in $10 \%$ neutral-buffered formalin, embedded in paraffin, sectioned at $4-\mu \mathrm{m}$ thickness, and stained with hematoxylin and eosin (H\&E; Sigma-Aldrich) or periodic acid-Schiff (PAS; Merck) to assess inflammatory cell infiltration, mucus production, and bronchial wall thickness. The percentage of mucus-secreting cells was calculated according to the ratio of the area occupied by PAS-stained goblet cells to that of all epithelial cells. The thickness of the bronchial wall was calculated as previously described ${ }^{11}$ based on the measurements of the lumen diameter and the outermost layers of smooth muscle across the longest and the shortest perpendicular axis in circular or oval bronchi with diameters of 110-150 $\mu \mathrm{m}$. Morphometric data were analyzed using Image J (NIH, Bethesda, MD, USA).

\section{Immunohistochemistry}

Lung tissue sections were deparaffinized, washed with $0.01 \mathrm{M}$ PBS ( $\mathrm{pH} 7.4$ ), and treated with $0.1 \%$ hydrogen peroxide in methanol for 15 min to block endogenous peroxidase activity. After washing in PBS, sections were incubated with blocking buffer (1\% bovine serum albumin) for $1 \mathrm{~h}$ and then with primary anti- $\alpha$-smooth muscle actin antibodies (rabbit IgG; Abcam, Cambridge, UK) diluted 1:200 overnight at $4^{\circ} \mathrm{C}$ in a humidified chamber. Sections were warmed at room temperature, washed in PBS, and incubated with biotinylated goat anti-mouse IgG (Vector Laboratories, Burlingame, CA, USA) for $2 \mathrm{~h}$, washed with PBS, and incubated with avidin-biotinylated complex (Vector Laboratories); 3,3'-diaminobenzidine (Sigma-Aldrich) was used to detect the signals. Sections were counterstained with hematoxylin, dehydrated, cleared, and mounted; actin-positive areas were photographed and measured using Motic Images Plus 2.0 (Motic China Co. Ltd, Xiamen, China). To correct for differences in bronchial size, actin-stained areas were normalized to the length of the basement membrane in sites with circular or oval bronchi of $110-150 \mu \mathrm{m}$ in diameter.

\section{Statistical analysis}

The data were expressed as the mean \pm standard error and statistically compared using Student's t-tests and one-way analysis of variance (ANOVA) with Tukey's post-hoc test; differences with $P$ values less than 0.05 were considered significant. Statistical analyses were performed using SPSS version 21 (IBM, Chicago, IL, USA).

\section{Results \\ Induction of obesity by high-fat diet}

Mice fed high-fat diet gained significantly more weight and showed about $47 \%$ increase compared to control mice $(32.55 \pm 0.13$ g versus $22.13 \pm 0.07 \mathrm{~g}$, respectively; $P<0.001)$; furthermore, they had significantly higher serum leptin levels compared to control mice (Figure 1), indicating successful establishment of an obesity model.

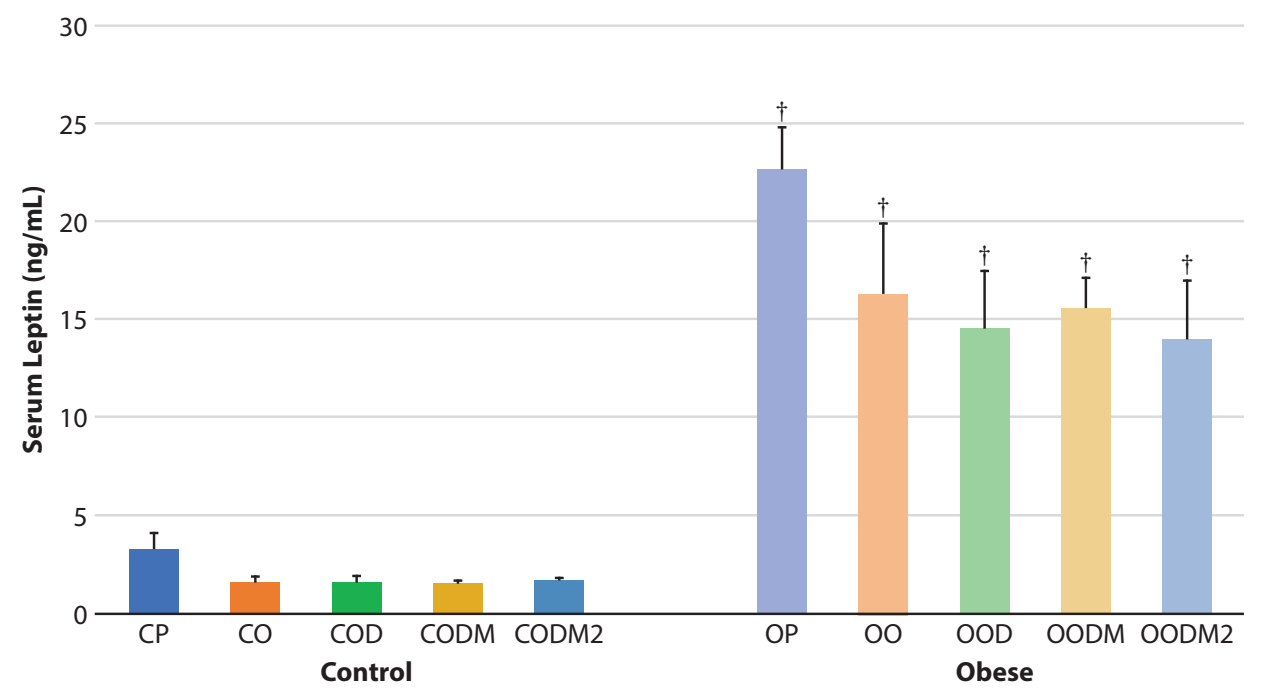

Figure 1. Effects of dexamethasone and $\mathrm{Mg}$ on serum leptin levels in normal and obese mice. ${ }^{\dagger} P<0.05$ compared with the corresponding group of normal mice. 


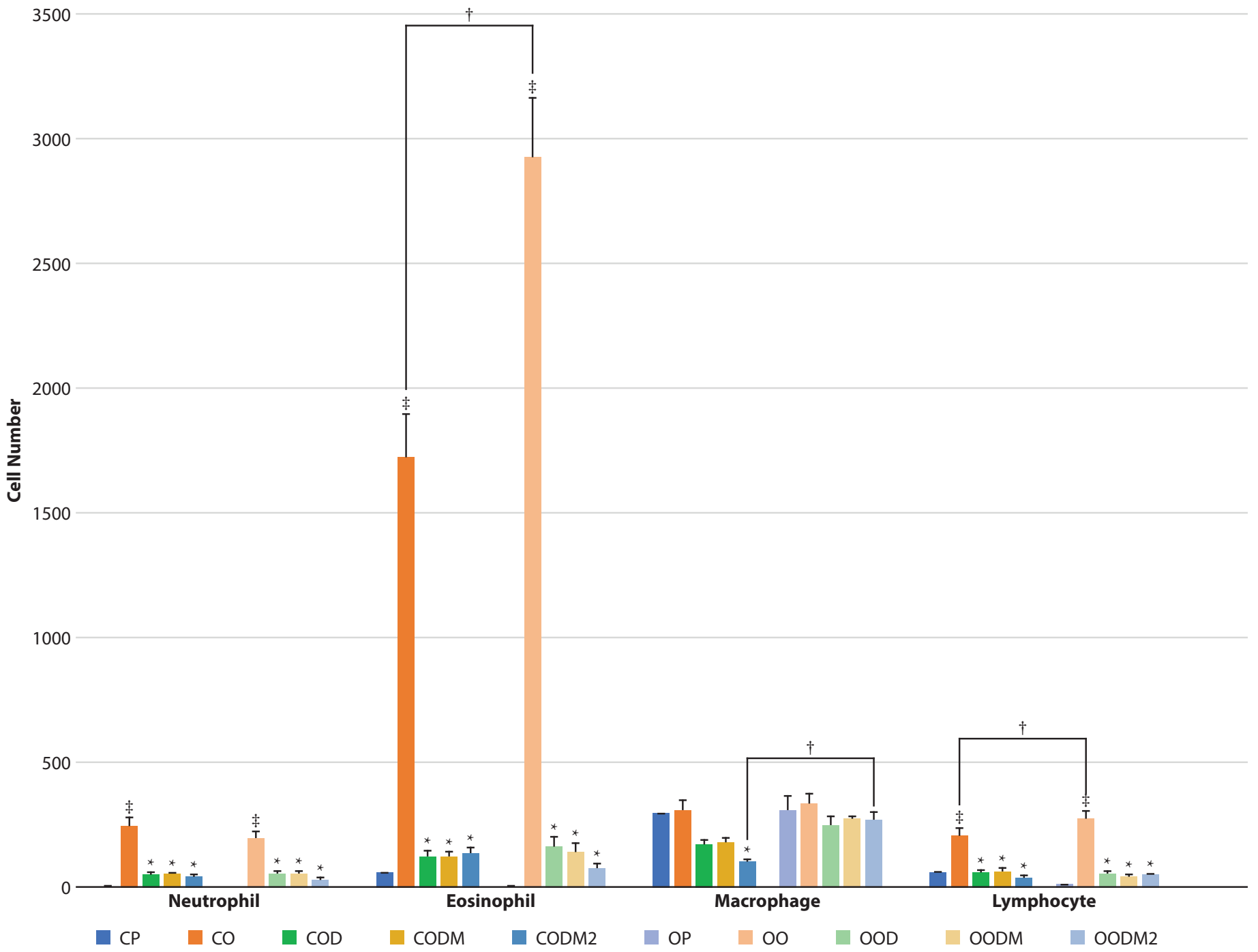

Figure 2. Effects of dexamethasone and $\mathrm{Mg}$ on the recruitment of inflammatory cells to bronchoalveolar lavage fluid. Mouse BALF was collected $48 \mathrm{~h}$ after final OVA challenge and stained using cytospin and Diff-Quik reagent. Cell numbers were counted within at least five hemocytometer squares under a light microscope. ${ }^{\ddagger} P<0.01$ compared with the $\mathrm{CP}$ or OP group respectively; ${ }^{\star} P<0.05$ compared with the $\mathrm{CO}$ or OO group, respectively; ${ }^{\dagger} P<0.05$ compared with the corresponding group of normal mice.

\section{Obesity enhances infiltration of eosinophils and lymphocytes into the lung}

Figure 2 presents immune cell counts in BALF. Compared with the $\mathrm{CO}$ and $\mathrm{OO}$ groups, mice treated with Dex and $\mathrm{Mg}$ had significantly lower neutrophil, eosinophil, and lymphocyte counts, whereas the reduction in macrophage counts was significant only in the CODM2 group compared to the CO group. There were no differences in inflammatory cell counts between groups treated with Dex alone or together with $\mathrm{Mg}$ either in normal or obese mice. The OO group had significantly higher counts of lymphocytes and eosinophils compared to the CO group, and the OODM2 group had significantly higher macrophage numbers compared to the CODM2 group.
Mg potentiates reduction of serum IgE by Dex in obese mice

In mice fed normal diet, serum levels of total IgE (Figure 3A) and OVA-specific IgE (Figure 3B) were significantly lower for OVA-sensitized groups treated with Dex alone or together with $\mathrm{Mg}$ (COD, CODM, and CODM2) compared to the $\mathrm{CO}$ group. In obese mice, total IgE was also significantly lower in all Dex-treated groups (OOD, OODM, and OODM2), whereas OVA-specific IgE was significantly lower in the OODM2 group compared with the OO group. There was no significant difference in total and OVA-specific $\operatorname{IgE}$ among the COD, CODM, and CODM2 groups; however, in obese mice, the OODM2 group had significantly lower levels of total IgE compared to the OOD group and OVA-specific IgE compared to the OOD and OODM groups. Comparison between normal and obese mice revealed that the OOD and OODM groups had significantly higher total serum IgE levels than the corresponding control groups (COD and CODM). 


\section{(A)}
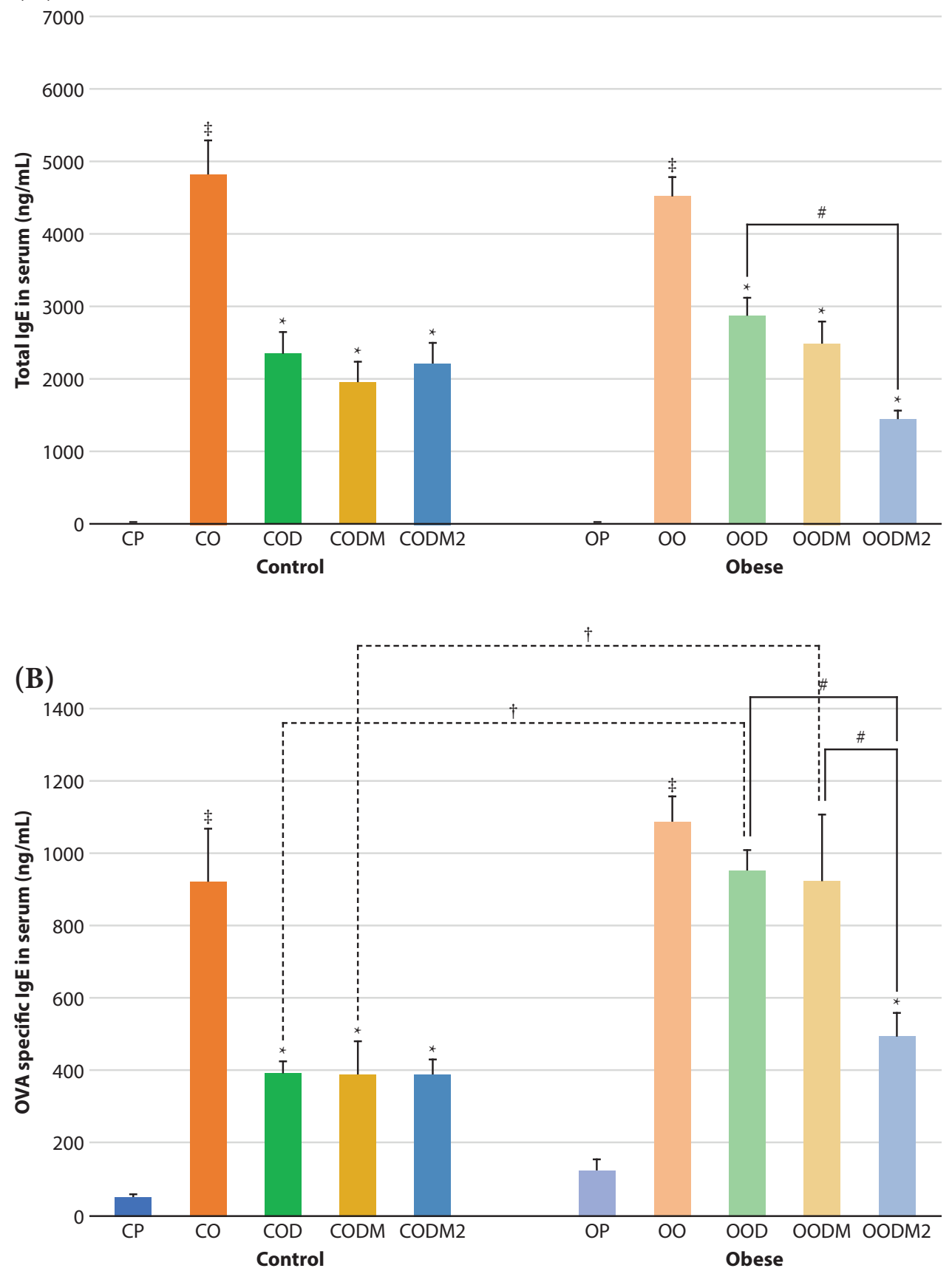

Figure 3. Effects of dexamethasone and $\mathrm{Mg}$ on serum IgE levels. (A) Total IgE and (B) OVA-specific IgE. ${ }^{\ddagger} P<0.01$ compared with the $\mathrm{CP}$ or $\mathrm{OP}$ group, respectively; ${ }^{\star} P<0.05$ compared with the $\mathrm{CO}$ or $\mathrm{OO}$ group, respectively; ${ }^{*} P<0.05$ among OOD, OODM and OODM2 groups; ${ }^{\dagger} P<0.05$ compared with the corresponding group of normal mice. 


\section{Mg promotes reduction of IL-13 levels in BALF of obese mice} Measurements of pro-inflammatory cytokines in BALF (Figure 4) indicated that in normal mice, IL-4 levels were significantly lower in the COD and CODM2 groups and IL-6 levels were significantly lower in the COD group compared to control (CO). Among obese mice, IL-4 and IL-6 levels were decreased in the OOD, OODM, and OODM2 groups; however, these changes were not significant. In addition, IL-13 levels were significantly lower in the OODM and OODM2 groups compared to the OO group, indicating that among obese mice, only those treated with Mg had significantly lower IL-13 levels, whereas no differences in IL-13 were observed among normal-weight mice. Furthermore, mice in the OODM and OODM2 groups had significantly lower IL-13 levels compared with normal mice subjected to the same treatment.

(A)

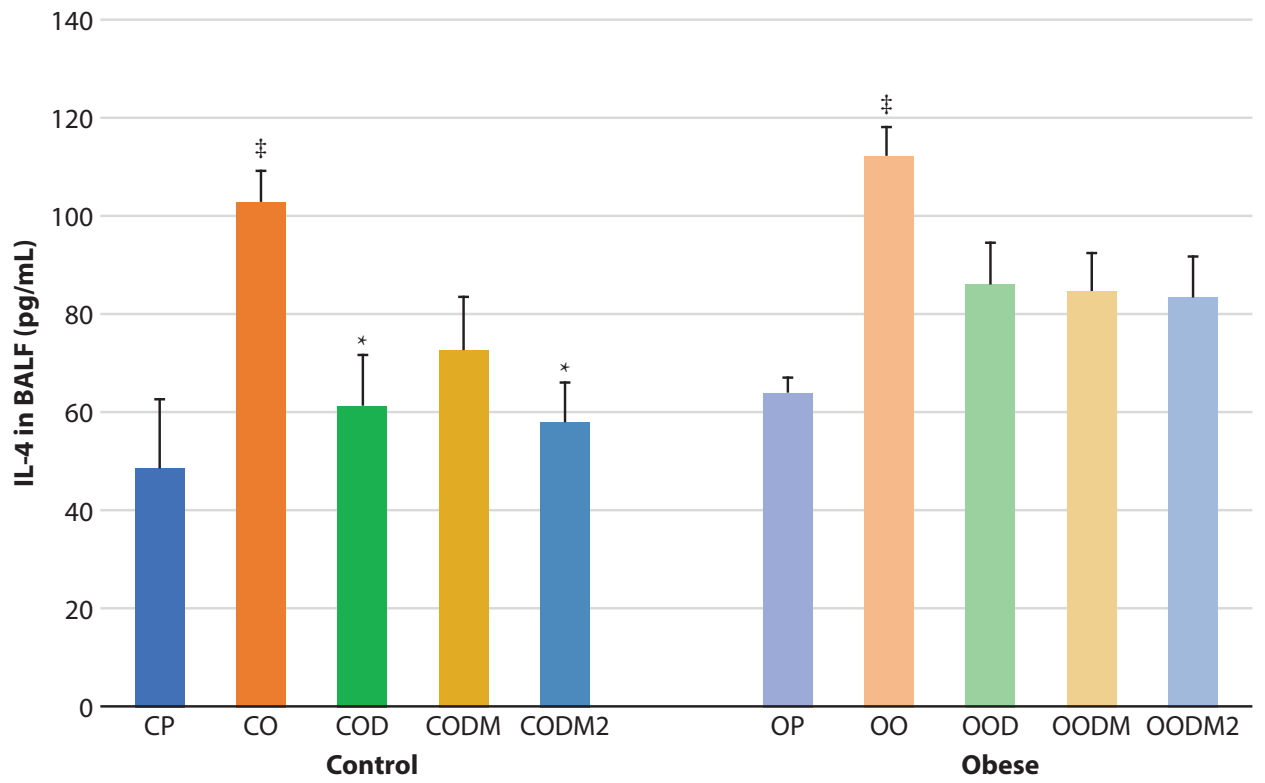

(B)

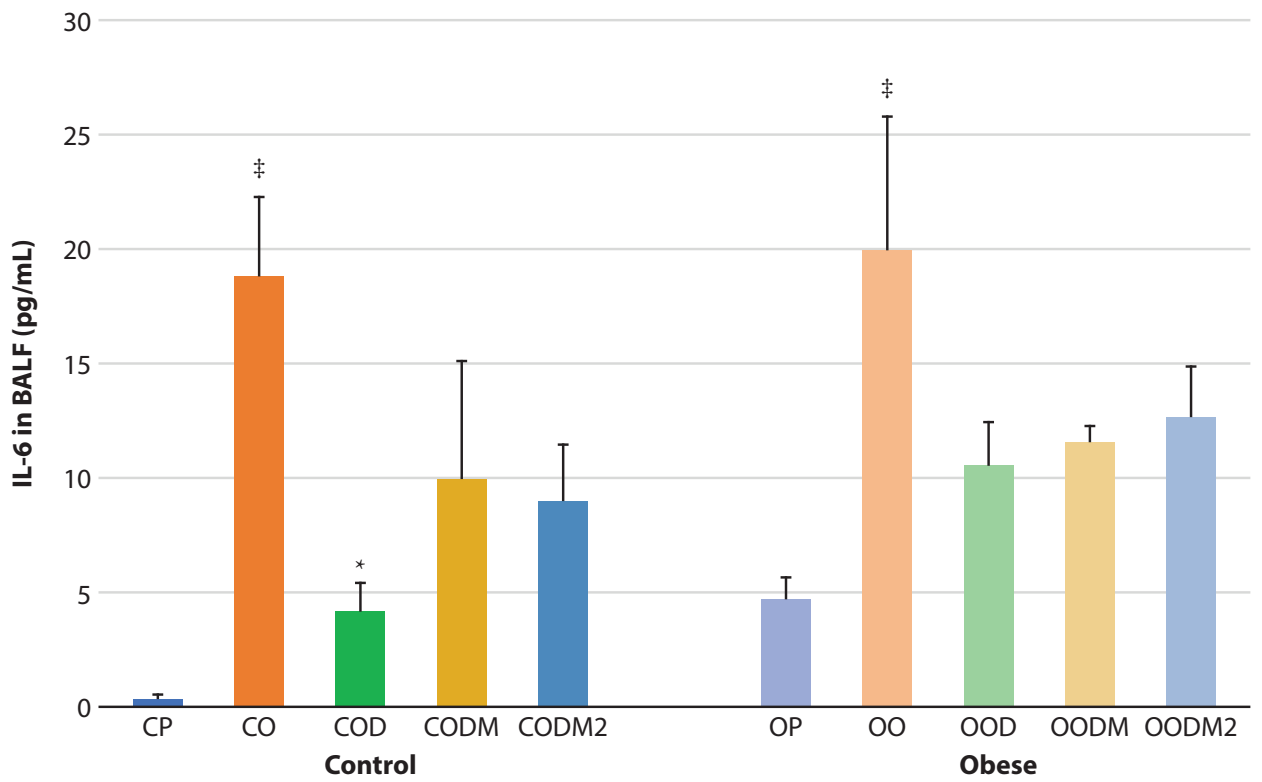

Figure 4. Effects of dexamethasone and Mg on Th2 cytokine levels in bronchoalveolar lavage fluid. (A) IL-4, (B) IL-6, and (C) IL-13. ${ }^{\ddagger} P<0.01$ compared with the $\mathrm{CP}$ or OP group, respectively; ${ }^{\star} P<0.05$ compared with the $\mathrm{CO}$ or OO group, respectively; ${ }^{\dagger} P$ $<0.05$ compared with the corresponding group of normal mice. 
(C)

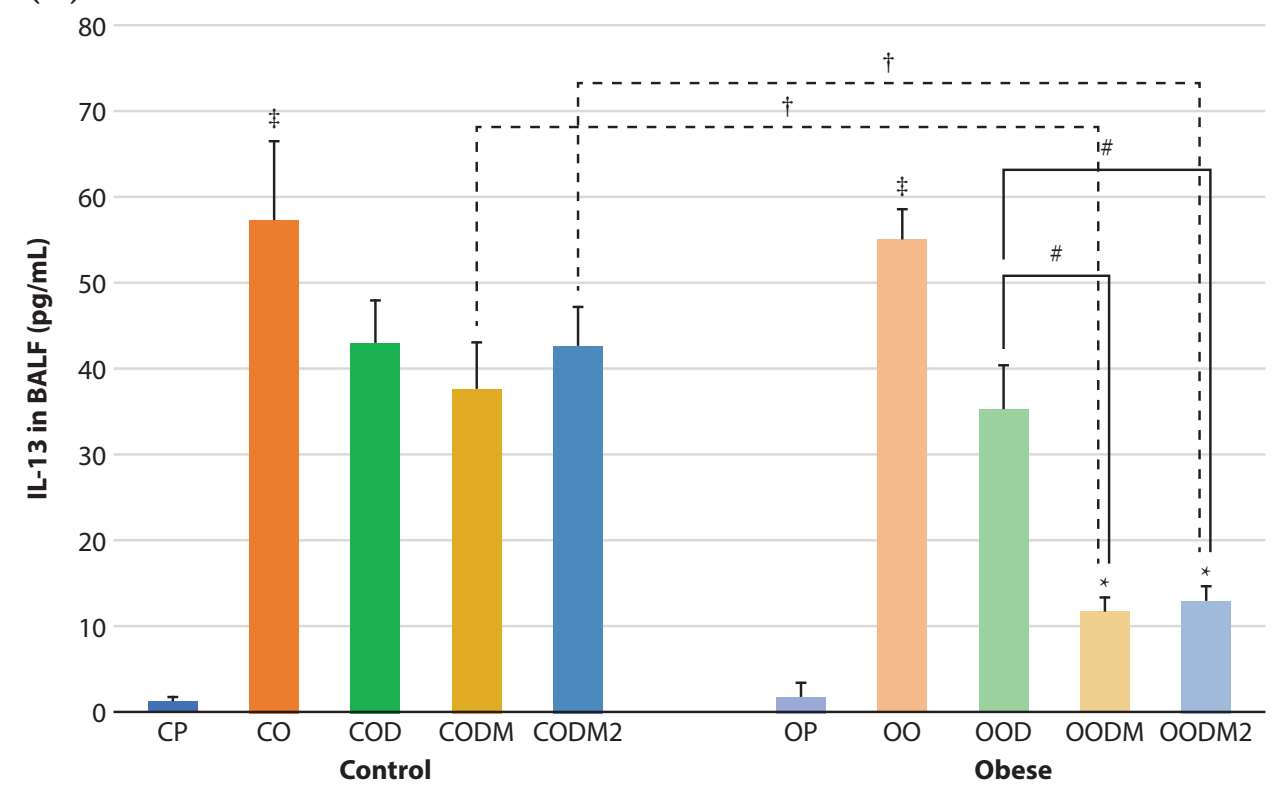

Figure 4. (Continued)

\section{Mg administration did not influence mucus-secreting cells}

The proportions of mucus-secreting goblet cells known to proliferate in asthma significantly decreased in the lung epithelium of all Dex-treated normal and obese mice compared to respective OVA-sensitized groups, with the exception of the CODM group (Figure 5A). However, there were no significant differences between mice treated with Dex only (COD and OOD) and those receiving Dex and $\mathrm{Mg}$ (CODM and CODM2 or OODM and OODM2, respectively) or between obese and normal mice.
Mg reduces hypertrophy of bronchial smooth muscle in obese mice

The thickness of the bronchial wall was significantly decreased in all Dex-treated groups of both normal and obese mice, with the exception of the CODM group, and Mg co-administration did not produce significant differences compared with Dex alone (Figure 5B). Moreover, there were no differences between obese and normal mice of the corresponding groups. Immunohistochemistry analysis showed that the expression of $a$-smooth muscle actin assessed by measuring

(A)

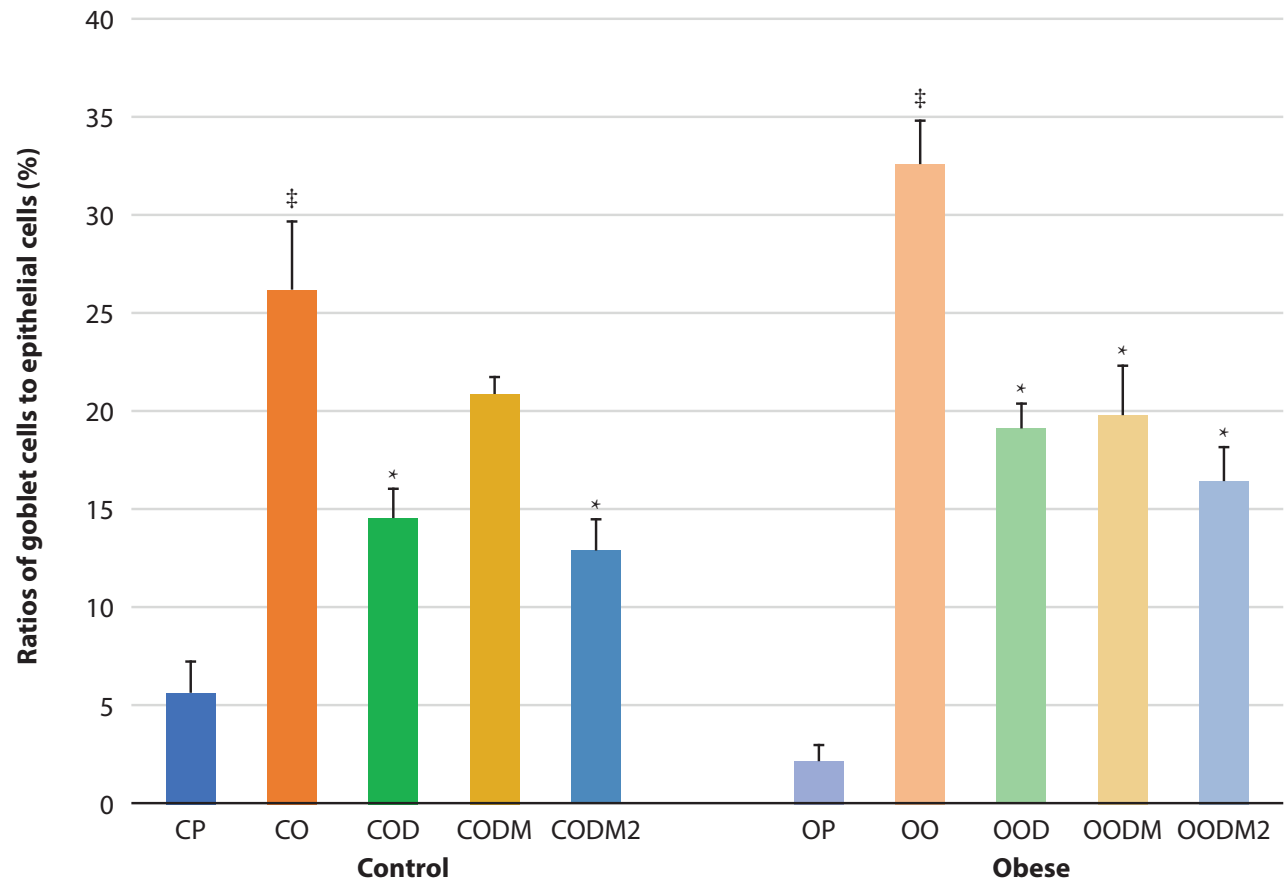

Figure 5. Effects of dexamethasone and $\mathrm{Mg}$ on airway wall. (A) The ratio of goblet cells to epithelial cells. (B) Airway wall thickness. (C) $\alpha$-Smooth muscle actin-positive areas. ${ }^{\ddagger} P<0.01$ compared with the $\mathrm{CP}$ or $\mathrm{OP}$ group, respectively; ${ }^{\star} P<0.05$ compared with the $\mathrm{CO}$ or $\mathrm{OO}$ group, respectively; ${ }^{*} P<0.05$ between $\mathrm{OOD}$ and OODM groups. 
(B)

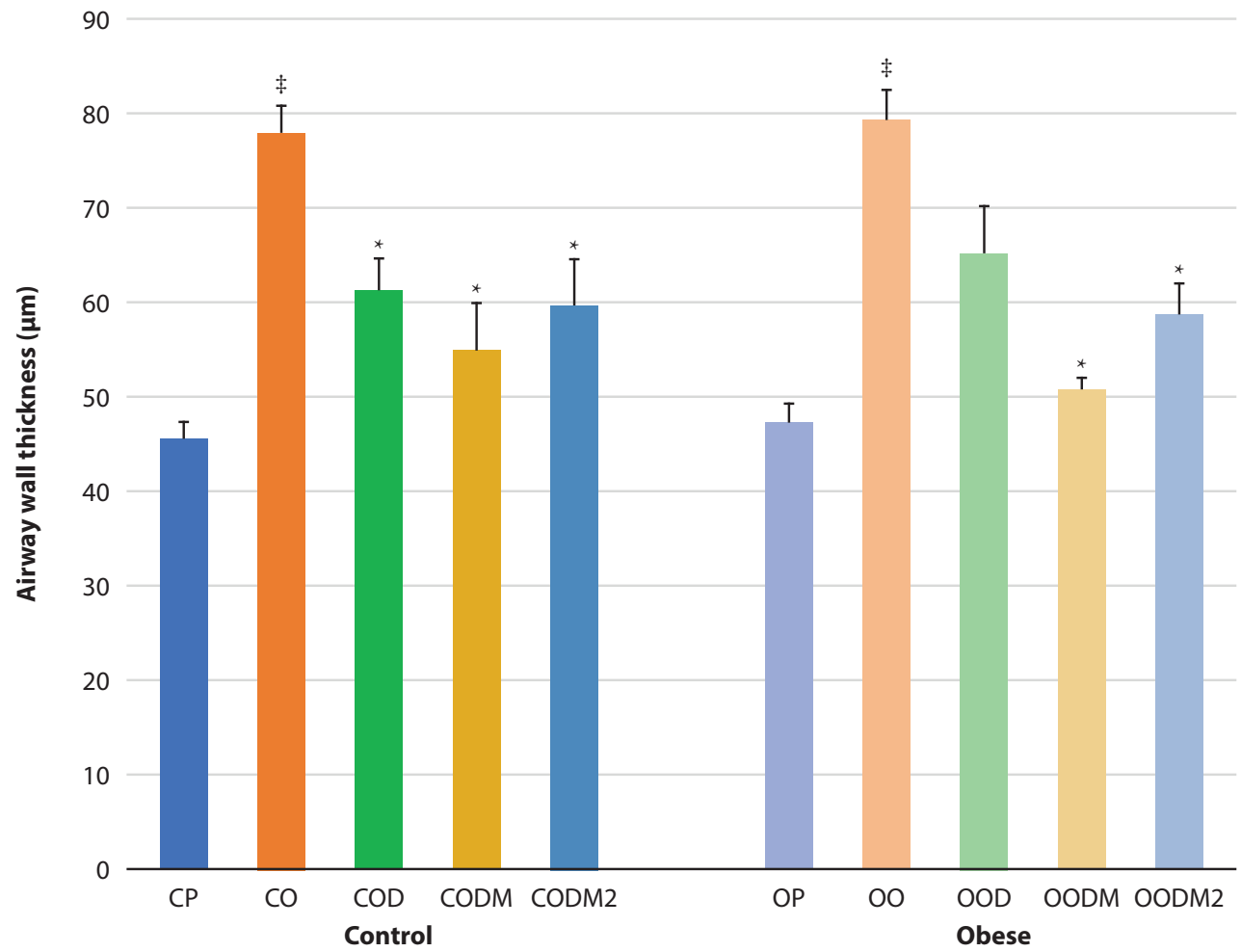

(C)

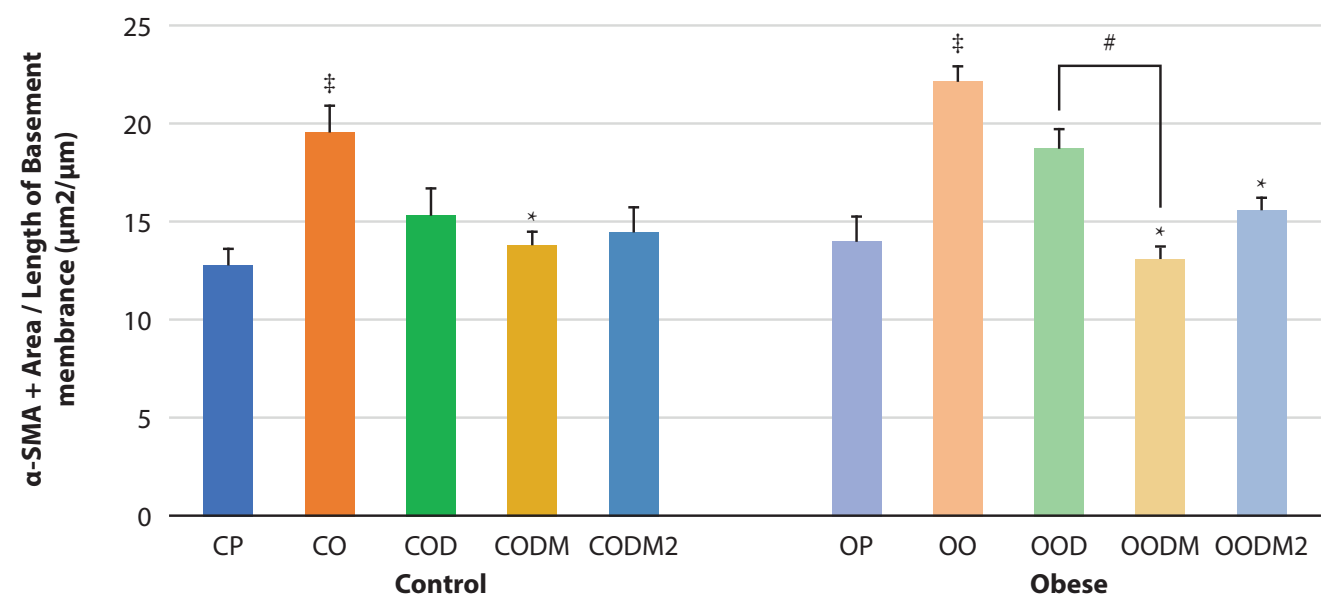

Figure 5. (Continued)

positively stained areas was significantly decreased in CODM as well as in OODM and OODM2 mice compared with untreated normal and obese mice ( $\mathrm{CO}$ and $\mathrm{OO}$ groups, respectively) (Figure 5C). In obese mice, co-administration of Dex and $\mathrm{Mg}$ at a low dose (OODM) caused a significant decrease in $a$-smooth muscle actin staining compared with mice treated with Dex only (OOD). These data indicate that Mg could potentiate a positive effect of Dex on smooth muscle hypertrophy in obese mice with inflammation in the lungs.

\section{Discussion}

Our findings show that obesity affected the severity of allergic airway inflammation and response to corticosteroid treatment in mice and that co-administration of $\mathrm{Mg}$ with Dex could reduce some inflammatory indices and bronchial smooth muscle cell proliferation in obese rather than in normal-weight mice.
In our model, obesity was induced by high-fat diet as indicated by significant weight gain and increased leptin levels compared to normal mice. Bronchial inflammation was stimulated by OVA as evidenced by increase in total and OVA-specific IgE levels and was somewhat stronger in obese than in normal mice judging by eosinophil and lymphocyte counts. However, these findings are at variance with those of Johnston et al., ${ }^{12}$ who showed a reduction in eosinophils in BALF for obese mice. Studies in asthma-induced animal models can yield contradictory results. Thus, Calixto et al..$^{13}$ reported that the number of inflammatory cells within BALF could vary depending on the time after immune response induction and that eosinophil levels were higher in obese mice than in normal-weight mice after $72 \mathrm{~h}$. It may explain the difference between our findings and those of Johnston et al., ${ }^{12}$ who performed measurements after $24 \mathrm{~h}$. Furthermore, Dietze et al. ${ }^{14}$ showed that bronchial eosinophil levels, 
but not mucus secretion, positively correlated with body weight, which is consistent with our current results.

Asthma is known to be associated with type 2 immune response, but we did not observe any difference in Th2 cytokine levels between obese and normal mice, which is in agreement with a previous report that obese mice exhibited increased airway hyper-responsiveness without involvement of the Th2 pathway. ${ }^{12}$ Sutherland et al. ${ }^{15}$ suggested that the relationship between obesity and asthma may be associated with the mechanisms linked to innate immunity.

In the present study, treatment with Dex alone significantly decreased IgE, IL-4, and IL-6 levels in normal-weight mice but not in obese mice, in which it also did not significantly reduce the thickness of the bronchial wall. These results are consistent with previous findings that obesity increases the utilization of inhaled steroids and $\beta$-agonists, thus preventing adequate symptom relief during asthma exacerbation, which is considered to be associated with blunted response of peripheral blood mononuclear cells to Dex observed in vitro. ${ }^{16,17}$ However, co-administration of Dex with $\mathrm{Mg}(200 \mathrm{mg} / \mathrm{kg})$ could reduce total and OVA-specific IgE in obese mice. Furthermore, $\mathrm{Mg}$ at both doses could significantly augment the reduction of IL-13 and at a low dose could reduce bronchial smooth muscle areas compared to obese mice treated with Dex only. The immunosuppressive effects of $\mathrm{Mg}$ in obesity can be explained by its antagonism with $\mathrm{Ca}$. Intracellular $\mathrm{Ca}$ influx, which is a prerequisite to increased production and secretion of pro-inflammatory factors, aggravates inflammation in the context of obesity and $\mathrm{Mg}$ deficiency and is known to enhance hyperplasia and hypertrophy of bronchial smooth muscle cells by promoting secretion of pro-inflammatory cytokines. $^{5,18}$

Studies on the clinical roles of $\mathrm{Mg}$ in obesity have typically been conducted in association with the metabolic syndrome that accompanies obesity and is manifested by insulin resistance, dyslipidemia, and hypertension. A clinical trial found that $\mathrm{Mg}$ supplementation reduced blood pressure in overweight adults with hypertension but did not affect that in individuals with normal blood pressure. ${ }^{19}$ Furthermore, oral $\mathrm{Mg}$ supplementation in adults improved bronchial response and the peak expiratory flow rate even without changes in Mg levels, suggesting that continuous Mg intake would have therapeutic effects in asthmatic patients because of increased demand for $\mathrm{Mg} .{ }^{20}$ Therefore, $\mathrm{Mg}$ co-administration could be an effective treatment regimen for patients with subclinical $\mathrm{Mg}$ deficiency and chronic low-grade bronchial inflammation caused by obesity and asthma. Our findings showing the effectiveness of $\mathrm{Mg}$ co-administration with Dex only in obese mice are consistent with this hypothesis.

This study has some limitations. First, we did not directly measure $\mathrm{Mg}$ levels. A previous study reported $\mathrm{Mg}$ deficiency in $40 \%$ of patients with asthma. ${ }^{21}$ However, for accurate assessment of $\mathrm{Mg}$ levels, they should be measured in serum, red blood cell, and urine as well as in the diet. $\mathrm{Mg}$ is an intracellular cation and its serum levels account for only about $1 \%$ of total $\mathrm{Mg}$ in the body; therefore, the intracellular level of $\mathrm{Mg}$ can be reduced without affecting that in serum, which makes it difficult to evaluate $\mathrm{Mg}$ deficiency and its clinical effects. Second, we did not have an experimental group receiving $\mathrm{Mg}$ only; therefore, it is unclear whether the effects of Dex $+\mathrm{Mg}$ co-administration are additive or synergistic. However, we believe that our model is clinically relevant because $\mathrm{Mg}$ has mild bronchodilating activity and is usually co-administered with steroids. Finally, although our study found that co-administration of $\mathrm{Mg}$ with Dex reduced the area of bronchial smooth muscle actin, the effect of $\mathrm{Mg}$ co-administration on bronchial remodeling could be more adequately assessed by prolonging the antigen exposure period. Leigh et al. ${ }^{22}$ compared bronchial remodeling during acute and chronic bronchial inflammation in mice and found different responses; thus, acute inflammation increased bronchial smooth muscle areas and goblet cell proliferation, whereas chronic inflammation increased deposition of extracellular matrix and airway hyper-responsiveness, which persisted for 8 weeks after challenge.

\section{Conclusions}

This study suggests that Mg co-administered with a steroid drug has immunosuppressive effects by decreasing some inflammatory indices and blocking bronchial smooth muscle cell proliferation in mice with obesity-associated allergic airway inflammation. These results should be validated in clinical trials to confirm that $\mathrm{Mg}$ supplementation could be a new therapeutic strategy for obesity-associated asthma.

\section{Conflict of interest}

The authors declare no competing financial interests.

\section{References}

1. Ford ES. The epidemiology of obesity and asthma. J Allergy Clin Immunol. 2005;115(5):897-909.

2. Beuther DA, Sutherland ER. Overweight, obesity, and incident asthma: a meta-analysis of prospective epidemiologic studies. Am J Respir Crit Care Med. 2007;175(7):661-6.

3. Thomson CC, Clark S, Camargo CA Jr, MARC Investigators. Body mass index and asthma severity among adults presenting to the emergency department. Chest. 2003;124(3):795-802.

4. Peters-Golden M, Swern A, Bird SS, Hustad CM, Grant E, Edelman JM. Influence of body mass index on the response to asthma controller agents. Eur Respir J. 2006;27(3):495-503.

5. Nielsen FH. Magnesium, inflammation, and obesity in chronic disease. Nutr Rev. 2010;68(6):333-40.

6. Tam M, Gómez S, González-Gross M, Marcos A. Possible roles of magnesium on the immune system. Eur J Clin Nutr. 2003;57(10):1193-7.

7. Kew KM, Kirtchuk L, Michell CI. Intravenous magnesium sulfate for treating adults with acute asthma in the emergency department. Cochrane Database Syst Rev. 2014;28(5):CD010909.

8. Cairns CB, Kraft M. Magnesium attenuates the neutrophil respiratory burst in adult asthmatic patients. Acad Emerg Med. 1996;3(12):1093-7.

9. Kazaks AG, Uriu-Adams JY, Albertson TE, Shenoy SF, Stern JS. Effect of oral magnesium supplementation on measures of airway resistance and subjective assessment of asthma control and quality of life in men and women with mild to moderate asthma: a randomized placebo controlled trial. J Asthma. 2010;47(1):83-92.

10. Kim Y, Lee MY, Kim OS, Jeon WY, Shin HK. Acute oral toxicity of Insampaedok-san, a traditional herbal formula, in rats and its protective effects against ovalbumin-induced asthma via anti-inflammatory and antioxidant properties. BMC Complement Altern Med. 2014;14:365.

11. Sun LZ, Elsayed S, Bronstad AM, Van Do T, Irgens A, Aardal NP, et al. Airway inflammation and bronchial remodelling in toluene diisocyanate -exposed BALB/c mouse model. Scand J Immunol. 2007;65(2):118-25.

12. Johnston RA, Zhu M, Rivera-Sanchez YM, Lu FL, Theman TA, Flynt L. Allergic airway responses in obese mice. Am J Respir Crit Care Med. 2007;176(7):650-8. 


\section{APJAI}

13. Calixto MC, Lintomen L, Schenka A, Saad MJ, Zanesco A, Antunes E. Obesity enhances eosinophilic inflammation in a murine model of allergic asthma. Br J Pharmacol. 2010;159(3):617-25.

14. Dietze J, Böcking C, Heverhagen JT, Voelker MN, Renz H. Obesity lowers the threshold of allergic sensitization and augments airway eosinophilia in a mouse model of asthma. Allergy. 2012;67(12):1519-29.

15. Sutherland TJ, Cowan JO, Young S, Goulding A, Grant AM, Williamson A, et al. The association between obesity and asthma: interactions between systemic and airway inflammation. Am J Respir Crit Care Med. 2008;178(5):469-75.

16. Taylor B, Mannino D, Brown C, Crocker D, Twum-Baah N, Holguin F. Body mass index and asthma severity in the National Asthma Survey. Thorax. 2008;63(1):14-20.

17. Sutherland ER, Goleva E, Strand M, Beuther DA, Leung DY. Body mass and glucocorticoid response in asthma. Am J Respir Crit Care Med. 2008;178(7):682-7.

18. Black JL, Panettieri RA Jr, Banerjee A, Berger P. Airway smooth muscle in asthma: just a target for bronchodilation. Clin Chest Med. 2012;33(3): 543-58.
19. Lee S, Park HK, Son SP, Lee CW, Kim IJ, Kim HJ. Effects of oral magnesium supplementation on insulin sensitivity and blood pressure in normo -magnesemic nondiabetic overweight Korean adults. Nutr Metab Cardiovasc Dis. 2009;19(11):781-8.

20. Kazaks AG, Uriu-Adams JY, Albertson TE, Shenoy SF, Stern JS. Effect of oral magnesium supplementation on measures of airway resistance and subjective assessment of asthma control and quality of life in men and women with mild to moderate asthma: a randomized placebo controlled trial. J Asthma. 2010;47(1):83-92.

21. Hashimoto Y, Nishimura Y, Maeda H, Yokoyama M. Assessment of magnesium status in patients with bronchial asthma. J Asthma. 2000;37 (6):489-96.

22. Leigh R, Ellis R, Wattie J, Southam DS, De Hoogh M, Gauldie J, et al Dysfunction and remodeling of the mouse airway persist after resolution of acute allergen-induced airway inflammation. Am J Respir Cell Mol Biol. 2002;27(5):526-35. 